\title{
The Effect of Gas Flow on Plasma Parameters Induced by Microwave
}

\author{
Sabah N. Mazhir ${ }^{1 *}$ \\ Noha H. Harb ${ }^{1}$
}

\author{
Nada A. Abdullah ${ }^{1}$ \\ Nisreen K. Abdalameer ${ }^{1}$
}

Received 17/12/2017, Accepted 22/4/2018, Published 4/6/2018

\begin{abstract}
:
In this paper, construction microwaves induced plasma jet(MIPJ) system. This system was used to produce a non-thermal plasma jet at atmospheric pressure, at standard frequency of $2.45 \mathrm{GHz}$ and microwave power of $800 \mathrm{~W}$. The working gas Argon (Ar) was supplied to flow through the torch with adjustable flow rate by using flow meter, to diagnose microwave plasma optical emission spectroscopy(OES) was used to measure the important plasma parameters such as electron temperature $(\mathrm{Te})$, residence time $\left(\mathrm{R}_{\mathrm{t}}\right)$, plasma frequency $\left(\omega_{\mathrm{pe}}\right)$, collisional skin depth $(\delta)$, plasma conductivity $\left(\sigma_{\mathrm{dc}}\right)$, Debye length $\left(\lambda_{\mathrm{D})}\right.$. Also, the density of the plasma electron is calculated with the use of Stark broadened profiles.
\end{abstract}

Key words: Boltzmann plot, Plasma parameters, Microwave plasma jet, Plasma diagnostics.

\section{Introduction:}

Plasma is commonly an ionized gas. It is combining of charge particles (electron, ion and molecules). The term ionized return to the existence of one or more free electron. That are not required to an atom or molecules $(1,2)$. It has free charge particles where the positive and negative charges approximately stasis each other at the level of the macroscopic. It resulted when the elements are heated to temperature more than the thermal energies and above binding energies for special state of matter. When the environment temperature increases the division of atoms can break down to negative charge electron and positive charge ion. These particles will contact with each other through the e.m. radiation(3). A microwave plasma is a type of plasma that has a high frequency electromagnetic radiation in the $\mathrm{GHz}$ range. Microwave generated plasma devices are preferred over other types of plasma sources because they are electrodeless plasma, so the mission of replacing or cleaning the electrodes and filaments is avoided. More importantly, the plasma is free from impurities that can come from the sputtering or evaporation of these parts during operation. This plasma can be excited in special geometries, and it can provide stable, continuous plasmas over a large range of gas pressures $(4,5)$.

\footnotetext{
${ }^{1}$ Department of Physics, College of Science for Women, University of Baghdad, Iraq

${ }^{2}$ Biotechnology Research Center, Al-Nahrain University, Iraq.

*Corresponding authors: dr_sabah68@yahoo.com
}

This paper presents the experimental work including the design and construction of a microwave plasma system, its operation at atmospheric pressure at standard frequency of 2.45 $\mathrm{GHz}$ and microwave power not exceeding $800 \mathrm{~W}$. The atmospheric-pressure microwave plasma parameters were determined by optical emission spectroscopy (OES) method. The Boltzmann plot method was used to calculate excitation temperature of argon, and the electron density was calculated by local thermal equilibrium assumption $(6,7,8)$.

\section{Materials and Methods: \\ Electron Temperature:}

In this work, Electron temperature (Te) was determined using Boltzmann plot method. In this method, several spectral lines are considered (represent ArI); all of these lines have a similar lower energy level $\mathrm{E}_{\mathrm{i}}$ with different upper energy levels $\mathrm{E}_{\mathrm{k}}$. Five lines have been chosen $(696.54,763.51,772.37,801.47$ and 811.53) nm (9). Table 1 lists argon lines considered with their spectroscopic data; these values of the parameters have been taken from NIST(10).

Table 1. Spectroscopic data of ArI lines used in Boltzmann plot method(7).

\begin{tabular}{llllll}
\hline Species & $\begin{array}{l}\text { Wavelength } \\
(\mathrm{nm})\end{array}$ & $\begin{array}{l}\mathrm{Ak} \times 10^{6} \\
\left(\mathrm{~s}^{-1}\right)\end{array}$ & $E_{i}(\mathrm{eV})$ & $E_{k}(\mathrm{eV})$ & $g_{k}$ \\
\hline ArI & 696.54 & 6.39 & 11.54 & 13.32 & 3 \\
ArI & 763.51 & 24.5 & 11.54 & 13.17 & 5 \\
ArI & 772.37 & 5.18 & 11.54 & 13.15 & 3 \\
ArI & 801.47 & 9.28 & 11.54 & 13.09 & 5 \\
ArI & 811.53 & 33.1 & 11.54 & 13.07 & 7 \\
\hline
\end{tabular}


To determine the electron temperature by using the following equation: (2)

$\operatorname{Ln}\left(\frac{I_{j i} \lambda_{j i}}{A_{j i} g_{j}}\right)=-\frac{E_{j}}{k T}+C$

where $C$ is a constant and substitute values of $A_{k}, E_{k}$ and $g_{k}$ from Table (1) . Now, by plotting the term $\operatorname{Ln}\left(\frac{I_{j i} \lambda_{j i}}{A_{j i} g_{j}}\right)$ in the vertical axis with $E_{j}$ in the horizontal axis from equation (1) for several lines (all of these lines have the same lower energy level), the electron temperature $T_{e}$, which is related to the slope of the linear fitting $(11,12,13)$.

\section{Electron Density}

The electron density $\left(n_{e}\right)$ was calculated using the following equation

$n_{e}=\exp \left(44.2476+1.20 \operatorname{Ln} \Delta \lambda_{\frac{1}{2}}-0.6 \operatorname{Ln} T_{e}\right)$

(3)

The Stark broadening (full width at halfmaximum, FWHM) $\Delta \lambda_{1 / 2}$ of the spectral line ArI $(696.54 \mathrm{~nm})$ line was measured from emission spectra and substituted in equation (3) with the values of $T_{e}$ (that obtained from equation (2))(14).

\section{Electron Residence Time}

Equation (4) clarifies the time of particles existence in the plasma(15):

$R_{t}=\frac{L_{j} A}{u}$

The electron residence time $\left(\mathrm{R}_{\mathrm{t}}\right)$ was calculated after substituting the value of plasma flame length $\mathrm{L}_{\mathrm{j}}$ with different gas flow rates.

\section{Plasma Frequency}

These oscillations occur at a frequency called the plasma frequency of electron $\left(\omega_{\text {pe }}\right)$ which can be written as (16):

$\omega_{p e}=\sqrt{\frac{e^{2} n_{e}}{\varepsilon_{0} m_{e}}}$

The plasma frequency $\omega_{\mathrm{p}}$ was calculated after substituted the $n_{e}$ from equation (3). The results show that $\omega_{\mathrm{p}}$ was on the order $10^{13} \mathrm{H}_{\mathrm{Z}}$ which exceeds the microwave frequency $2.45 \times 10^{9} \mathrm{H}_{\mathrm{Z}}$ that is used to create our plasma in four orders.

\section{The Collisional Skin Depth}

Collisional skin depth $(\delta)$ of plasma was calculated from the following equation:

$\delta=\frac{c}{\omega_{p}} \sqrt{\frac{2 v_{m}}{\omega}}$

where $c$ is the speed of light in a vacuum, $\omega_{p}$ is the frequency of plasma, $v_{m}$ is the frequency of momentum collision, and $\omega$ is the frequency of microwave.

whereas this equation valid $\omega_{p e}, v_{m} \gg \omega$ and that verified by estimated momentum collision frequency $v_{m}$ from equations

$v_{m}=v \frac{m_{1}+m_{2}}{2 m_{1}}$

which were given values in order $10^{15} \mathrm{H}_{\mathrm{Z}}$.

\section{Plasma Conductivity}

Equation (8) clarifies the plasma conductivity, $\sigma_{d c}$, is given by

$\sigma_{\mathrm{dc}}=\frac{2}{\omega \mu_{\mathrm{o}} \delta^{2}}$

where $\omega$ is the frequency of microwave, $\mu_{o}$ is the constant of vacuum permeability, and $\delta$ is the collisional skin depth.

\section{Debye length}

The applied electrical potential will therefore develop mostly near the surfaces, over a distance $\lambda_{D}$, called the Debye length as defined by $(17,18)$.

$$
\lambda_{D}=\left(\frac{\varepsilon_{o} k_{B} T_{e}}{n_{e} e^{2}}\right)^{1 / 2}
$$

where $\mathrm{n}_{\mathrm{e}}$ is the density of the electrons $\left(m^{-3}\right), \varepsilon_{\mathrm{O}}$ is Permittivity of free space

\section{Experimental setup:}

The diagram of the setup used for experimental investigations of microwave plasma sources is shown in Fig. 1. Its essential components are: Microwave generator (magnetron), Tapered rectangular waveguide, Plasma discharge tube, Ignition system, Gas supply and flow controller.

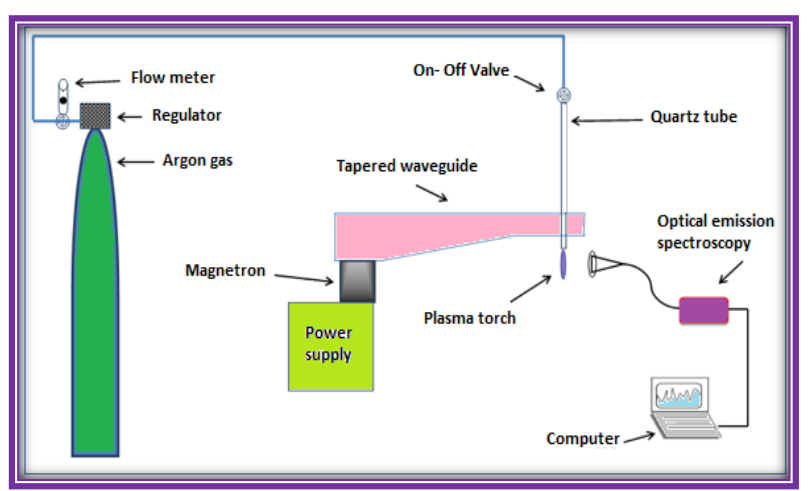

Figure 1. A schematic diagram of the microwaves induced plasma jet system.

The first step of this paper is applied a variable input AC voltage on the microwave source (magnetron) ranged from 150 to 220 volt. After operating the magnetron, argon as a working gas was inserted through a discharge quartz tube with diameter $10 \mathrm{~mm}$ at different flow rates $(1,2,3,4$ and 5 ) $\ell / m i n$. Optical emission spectroscopic was used to measure a microscopic parameters of the plasma jet such as electron temperature and electron density.

\section{Results and Discussions:}

Figure 2 illustrates the Boltzmann plot for the equation 2 for single case. With the diagnostic method described above, electron temperatures measured as gas flow rate, discharge tube diameter $10 \mathrm{~mm}$ and applied voltage varied in the ranges (15) $\mathrm{emin}^{-1}$, of 150-220Volt. As shown in Fig. 3 which shows the relation between electron 
temperatures and applied voltage at a different gas flow rate. At the beginning of the operation, the gas flow rate was $1 \mathrm{l} / \mathrm{min}$ the electron temperature was $0.07778 \mathrm{eV}$ at 150 volts; this value remains the same before the microwave (0v). The electron temperature increases with voltage until it reaches $0.19232 \mathrm{eV}$ at $190 \mathrm{v}$ after $190 \mathrm{v}$. The value decreases to $0.1601 \mathrm{eV}$ at $200 \mathrm{v}$ and remains constant for higher voltage. For all the other gas flow rates ( 2 to 5) $\ell / \mathrm{min}$, the electron temperature at $0 \mathrm{v}$ has the value of $0.04 \mathrm{eV}$. At $2 \mathrm{l} / \mathrm{min}$ the electron temperature starts at a value of $0.11723 \mathrm{eV}$ and reach its maximum value $0.21317 \mathrm{eV}$ at $170 \mathrm{v}$. The electron temperature decreases at a voltage range from $170 \mathrm{v}$ to $190 \mathrm{v}$ and for higher voltage, the electron temperature remains approximately constant. For $3 \mathrm{l} / \mathrm{min}$ curve the electron temperature at $150 \mathrm{v}$ was $0.1803 \mathrm{eV}$ and this value decreases to $0.14078 \mathrm{eV}$ at $160 \mathrm{v}$. The electron temperature remains constant at a voltage higher than $160 \mathrm{v}$. At 4 $\ell /$ min curve the value of electron temperature was constant for all applied voltages with the value of $0.14072 \mathrm{eV}$ except at $160 \mathrm{v}$ where the electron temperature was $0.10646 \mathrm{eV}$. The $5 \mathrm{l} / \mathrm{min}$ curve shows the least electron temperature at any voltage. The electron temperature was $0.02633 \mathrm{eV}$ at $150 \mathrm{v}$ and increases to $0.10646 \mathrm{eV}$ at $160 \mathrm{v}$. At a higher voltage, the electron temperature varied between 0.1 and $0.15 \mathrm{eV}$.

Figure 4 demonstrates the electron density as a function of applied voltage at a different gas flow rate. Before the microwave at $(0 \mathrm{v})$ the electron density for $1 \mathrm{l} / \mathrm{min}$ gas flow rate was $9.22 \mathrm{E}+16 \mathrm{~cm}^{-}$ ${ }^{3}$, but for the gas flow rate range from 2 to $5 \mathrm{l} / \mathrm{min}$ the average electron density was $1.3 \mathrm{E}+17 \mathrm{~cm}^{-3}$.The maximum value of electron density was $3.16482+\mathrm{E} 17 \mathrm{~cm}^{-3}$ for $3 \mathrm{l} / \mathrm{min}$ at 180 volts flowed by $2.91345 \mathrm{E}+17 \mathrm{~cm}^{-3}$ at $200 \mathrm{v}$. The minimum value for $3 \mathrm{\ell} / \mathrm{min}$ at range from $150 \mathrm{v}$ to $160 \mathrm{v}$ was less than $1 \mathrm{E}+17$.For $4 \mathrm{l} / \mathrm{min}$ gas flow the major value lies between $170 \mathrm{v}$ to $210 \mathrm{v}$ at electron density range from $2 \mathrm{E}+17 \mathrm{~cm}^{-3}$ to $3 \mathrm{E}+17 \mathrm{~cm}^{-3}$. The maximum value for electron density at $1 \mathrm{\ell} / \mathrm{min}$ gas flow was $2.18179 \mathrm{E}+17 \mathrm{~cm}^{-3}$ at $170 \mathrm{v}$, the rest of the values were less than $1.5 \mathrm{E}+17 \mathrm{~cm}^{-3}$. The bar chart for 5 $\ell /$ min at $150 \mathrm{v}$ shows the electron density was $1.76974 \mathrm{E}+17 \mathrm{~cm}^{-3}$ which represents the maximum value. At voltage range from $160 \mathrm{v}$ to $220 \mathrm{v}$, the electron density was less than $1 E+17 \mathrm{~cm}^{-3}$. At 2 $\ell /$ min all the values of electron density were less than $1 \mathrm{E}+17 \mathrm{~cm}^{-3}$ for all applied voltages.

The change of electron residence time has been studied as a function of the applied voltage from 0 to 220 volts, where $0 \mathrm{v}$ means without a microwave. The different gas flow rates have been used as shown in Fig. 5. As the voltage increases, the electron residence time also increases, but when the gas flow rate increases the electron residence time decreases at any voltage.

The highest value of electron residence time is measured at $1 \mathrm{\ell} / \mathrm{min}$. At $0 \mathrm{v}$ the value was $188.4 \mathrm{msec}$ It increases rapidly with voltage until it reaches $438.03 \mathrm{msec}$ at $220 \mathrm{v}$. For any applied voltage, the drop of electron resistance time from 1 $\ell / \mathrm{min}$ to $2 \mathrm{l} / \mathrm{min}$ is significantly large. The electron residence time curve for gas flow rate ranges from 3 to $5 \mathrm{l} / \mathrm{min}$ which behave the same and their results are close to each other.

For $2 \mathrm{l} / \mathrm{min}$ gas flow rate, the electron residence time was $122.46 \mathrm{msec}$ at $0 \mathrm{v}$ and the maximum was $223.725 \mathrm{msec}$ at $220 \mathrm{v}$. For $3 \mathrm{l} / \mathrm{min}$ gas flow rate, the electron residence time was $89.91 \mathrm{msec}$ at $0 \mathrm{v}$ and the maximum was $161.71 \mathrm{msec}$ at $220 \mathrm{v}$. For $4 \mathrm{l} / \mathrm{min}$, the electron residence time was $88.315 \mathrm{msec}$ at $0 \mathrm{v}$ and the maximum was $131.88 \mathrm{msec}$ at $220 \mathrm{v}$. Finally, at $5 \mathrm{l} / \mathrm{min}$, the value was $73.476 \mathrm{msec}$ at $0 \mathrm{v}$ and the maximum was $113 \mathrm{msec}$ at $220 \mathrm{v}$.

In Fig. 6 the relation between the measured plasma frequency and the applied voltage at different gas flow rates is shown. The plasma frequency was measured at gas flow rates of $(1,2$, 3,4 and 5) $\ell / m i n$. At $1 \ell / m i n$ the plasma frequency was $1.71 \mathrm{E}+13 \mathrm{~Hz}$ at $0 \mathrm{v}$ where no microwave was ignited. The frequency increases gradually with the increase of voltage until it reaches the maximum frequency value of $2.63 \mathrm{E}+13 \mathrm{~Hz}$ at $170 \mathrm{v}$. At voltage range from $180 \mathrm{v}$ to $220 \mathrm{v}$ an average frequency was calculated and its value was $1.43 \mathrm{E}+13 \mathrm{~Hz}$. For 2 $\ell /$ min the frequency at $0 \mathrm{v}$ was $2.03 \mathrm{E}+13 \mathrm{~Hz}$ and at voltage range from $150 \mathrm{v}$ to $220 \mathrm{v}$ the average frequency was $1.53 \mathrm{E}+13 \mathrm{~Hz}$. For $3 \mathrm{l} / \mathrm{min}$ the frequency was $2.03 \mathrm{E}+13 \mathrm{~Hz}$ at $0 \mathrm{v}$. The frequency decreases to its minimum of $1.47 \mathrm{E}+13 \mathrm{~Hz}$ at $150 \mathrm{v}$ and remains constant at $160 \mathrm{v}$ then the frequency increases with voltage above $170 \mathrm{v}$ until it reaches its maximum value of $2.63 \mathrm{E}+13 \mathrm{~Hz}$ at $180 \mathrm{v}$. The behavior of $4 \mathrm{l} / \mathrm{min}$ bar chart is similar to $3 \mathrm{l} / \mathrm{min}$ where it starts with frequency of $2.03 \mathrm{E}+13 \mathrm{~Hz}$ before the microwave then decreases to average minimum value of $1.5 \mathrm{E}+13 \mathrm{~Hz}$ at both 150 and $160 v$. Above 170v the frequency increases with voltage until it reaches the maximum value of $3.05 \mathrm{E}+13 \mathrm{~Hz}$ at $190 \mathrm{v}$ and the value drops slowly at higher voltage until it reaches $220 \mathrm{v}$ with frequency of $1.72 \mathrm{E}+13 \mathrm{~Hz}$. Finally the $5 \mathrm{~L} / \mathrm{min}$ has frequency of $2.06 \mathrm{E}+13 \mathrm{~Hz}$, reaching to its maximum at $150 \mathrm{v}$ where the frequency was $2.37 \mathrm{E}+13 \mathrm{~Hz}$. This value was the highest frequency measured at all gas flow rates. The frequency drops to average of $1.61 \mathrm{E}+13 \mathrm{~Hz}$ at voltage range from $160 \mathrm{v}$ to $220 \mathrm{v}$.

Fig. 7 shows the relationship between skin depth and applied voltage. The skin depth was calculated at different gas flow rates before and after the 
microwave at voltage rang from $150 \mathrm{v}$ to $220 \mathrm{v}$. The skin depth for $1 \ell / \mathrm{min}$ gas flow rate was $30.12788 \mathrm{~cm}$ before microwave. After the microwave the average skin depth at voltage range from $150 \mathrm{v}$ to $170 \mathrm{v}$ was $25.43 \mathrm{~cm}$ and the average skin depth for voltage range from $180 \mathrm{v}$ to $220 \mathrm{v}$ was $43.82 \mathrm{~cm}$.

At $2 \mathrm{l} / \mathrm{min}$ the skin depth was $22.13 \mathrm{~cm}$ at $0 \mathrm{v}$ where no microwave was ignited. The skin depth gradually increases with the increase of voltage until it reaches to the maximum value of $62.2 \mathrm{~cm}$ at $170 \mathrm{v}$. The rest of the values have less value than $44.9 \mathrm{~cm}$ at applied voltage range from $180 \mathrm{v}$ to $220 \mathrm{v}$. For $3 \mathrm{l} / \mathrm{min}$ the skin depth starts at $22.25 \mathrm{~cm}$ before the microwave and increases to $41.7 \mathrm{~cm}$ at both 150 and 160 volt. The skin depth at voltage ranges from $170 \mathrm{v}$ to $220 \mathrm{v}$ was represented as average and the value was $21.95 \mathrm{~cm}$. For $4 \mathrm{l} / \mathrm{min}$ the skin depth start at $21.99 \mathrm{~cm}$ before the microwave and increases to $41.7 \mathrm{~cm}$ at both 150 and 160 volt. The skin depth at voltage range from $170 \mathrm{v}$ to $220 \mathrm{v}$ was represented as average and the value was $21.95 \mathrm{~cm}$. Finally, the skin depth for $5 \mathrm{l} / \mathrm{min}$ gas flow rate before the microwave was $21.47 \mathrm{~cm}$ and the value increases to average of $35.6 \mathrm{~cm}$ at voltage range from $160 \mathrm{v}$ to $220 \mathrm{v}$. The plasma conductivity was measured before and after the microwave at different gas flow rates and the data were represented as shown in Fig. 8 between the plasma conductivity and the applied voltage. When the gas flow rate is $1 \mathrm{l} / \mathrm{min}$, the plasma before the microwave $(0 \mathrm{v})$ has a value of $0.71(\Omega \mathrm{m})^{-1}$. This value increased with the increase of applied voltage until it reached the maximum value of $1.26(\Omega \mathrm{m})^{-1}$ and the value dropped to an average conductivity of $0.348(\Omega \mathrm{m})^{-1}$ at voltage range from $180 \mathrm{v}$ to $220 \mathrm{v}$. At $2 \mathrm{l} / \mathrm{min}$ gas flow rate, the maximum value $1.33(\Omega \mathrm{m})^{-1}$ was indicated before the microwave. This value decreases with the increase of voltage until it reaches $0.17(\Omega \mathrm{m})^{-1}$ at $170 \mathrm{v}$, where this value is the minimum value. The conductivity increases again to average value of $0.428(\Omega \mathrm{m})^{-1}$ at voltage range from $180 \mathrm{v}$ to $220 \mathrm{v}$. For $3 \mathrm{l} / \mathrm{min}$ the conductivity was $1.34(\Omega \mathrm{m})^{-1}$ at $0 \mathrm{v}$ the conductivity decreases to its minimum of $0.37(\Omega \mathrm{m})^{-1}$ at $150 \mathrm{v}$ and remains constant at $160 \mathrm{v}$ then the conductivity increases with voltage above $170 \mathrm{v}$ until it reaches its maximum value of $1.83(\Omega \mathrm{m})^{-1}$ at $180 \mathrm{v}$. The behavior of $4 \mathrm{l} / \mathrm{min}$ bar chart is similar to $3 \mathrm{l} / \mathrm{min}$ where it starts with conductivity of $1.34(\Omega \mathrm{m})^{-1}$ before the microwave then decreases to average minimum value of $0.45(\Omega \mathrm{m})^{-1}$ at both 150 and $160 \mathrm{v}$. Above $170 \mathrm{v}$ the conductivity increases with voltage until it reaches the max value of $1.69(\Omega \mathrm{m})^{-1}$ at $190 \mathrm{v}$ and the value drops slowly at higher voltage until it reaches $220 \mathrm{v}$ with conductivity of 1 . Finally, the $5 \mathrm{l} / \mathrm{min}$ has conductivity of $1.41(\Omega \mathrm{m})^{-1}$ that reaches its maximum at $150 \mathrm{v}$, where the conductivity was $2.37(\Omega \mathrm{m})^{-1}$. This value was the highest conductivity measured at all gas flow rates. The conductivity drops quickly to average of $0.52(\Omega \mathrm{m})^{-1}$ at voltage range from $160 \mathrm{v}$ to $220 \mathrm{v}$.

Debye length was demonstrated as a function of the applied voltage as shown in Fig. 9. The data were represented as bar chart at a different gas flow rate. At $0 \mathrm{~V}$, it indicates that no microwave has been applied. The Debye length at gas flow rate range from 2 to $5 \mathrm{l} / \mathrm{min}$ has an average value of $4 \mathrm{E}-$ $6 \mathrm{~cm}$. At $1 \mathrm{l} / \mathrm{min}$ gas flow rate the value was $6.85 \mathrm{E}-$ $6 \mathrm{~cm}$. This value was higher than average Debye length of all other gas flow rates. When the microwave is applied to $1 \mathrm{l} / \mathrm{min}$ gas flow the Debye length starts with $5.96425 \mathrm{E}-06 \mathrm{~cm}$ at $150 \mathrm{v}$; this value remains nearly the same for $160 \mathrm{v}$ and $170 \mathrm{v}$, but at $180 \mathrm{v}$ the value increases to $1.15698 \mathrm{E}-05 \mathrm{~cm}$. The average Debye length value for the voltage range from $180 \mathrm{v}$ to $220 \mathrm{v}$ was $1.20958 \mathrm{E}-05 \mathrm{~cm}$. For 2 $\ell / m i n$ gas flow the maximum value for Debye length was $1.81779 \mathrm{E}-05 \mathrm{~cm}$ at $170 \mathrm{v}$. Values for other voltages were calculated as the average value of $1.02697 \mathrm{E}-05 \mathrm{~cm}$. Both $3 \mathrm{l} / \mathrm{min}$ and $4 \mathrm{l} / \mathrm{min}$ gas flow rates show similar behaviours and close results. Voltages from $150 \mathrm{v}$ to $160 \mathrm{v}$ have Debye length value that varies from $8 \mathrm{E}-06 \mathrm{~cm}$ to $1.2 \mathrm{E}-5 \mathrm{~cm}$. A voltage higher than 150 the Debye length has a value less than $6 \mathrm{E}-06 \mathrm{~cm}$. At $5 \mathrm{l} / \mathrm{min}$ gas flow rate the Debye length has the lowest value of $2.86915 \mathrm{E}$ $06 \mathrm{~cm}$ at $150 \mathrm{v}$; this value increases to $8.77561 \mathrm{E}-$ $05 \mathrm{cmat} 170 \mathrm{v}$. The average value was $8.99604 \mathrm{E}-$ $06 \mathrm{~cm}$ for voltage range from 170 to $220 \mathrm{v}$.

\section{Conclusions:}

This paper has evaluated the development which has been made experimentally on plasma parameters induced by Microwave. This was achieved by utilizing OES to determine plasma physical parameters. In addition, this paper studied the influence of applied voltage, argon gas flow rate on the microscopic characteristics (i.e. $T_{e}, n_{e}, R_{t}$, $\left.\omega_{\mathrm{p}}, \lambda_{\mathrm{mfp}}, \delta, \sigma_{\mathrm{cd}}\right)$ were studied as well. It is found that increasing the applied voltage increases the $T_{e}, R_{t}$ and $\delta$ but decreases the $\mathrm{n}_{\mathrm{e}}, \omega_{\mathrm{p}}$ and $\sigma_{\mathrm{cd}}$. In constrict, the increasing in the argon flow rate caused increase in $\mathrm{n}_{\mathrm{e}}, \omega_{\mathrm{p}}$ and $\sigma_{\mathrm{cd}}$ but decreased the $\mathrm{T}_{\mathrm{e}}, \mathrm{R}_{\mathrm{t}}$ and $\delta$. 


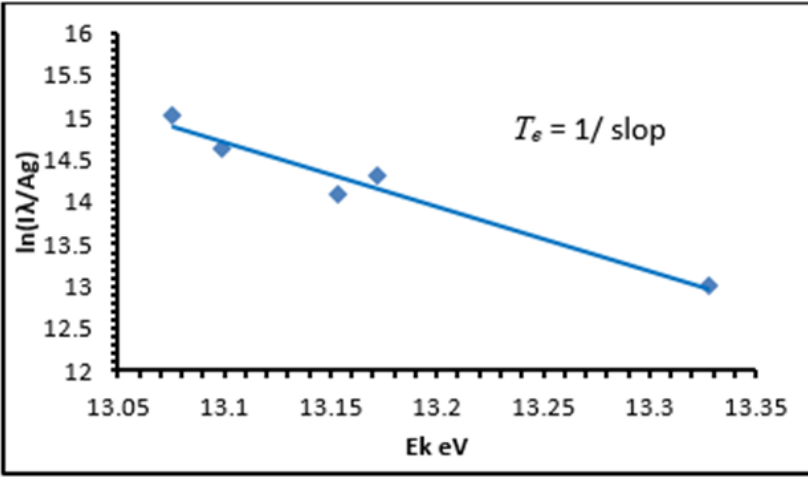

Figure 2. The Boltzmann plot method for single case

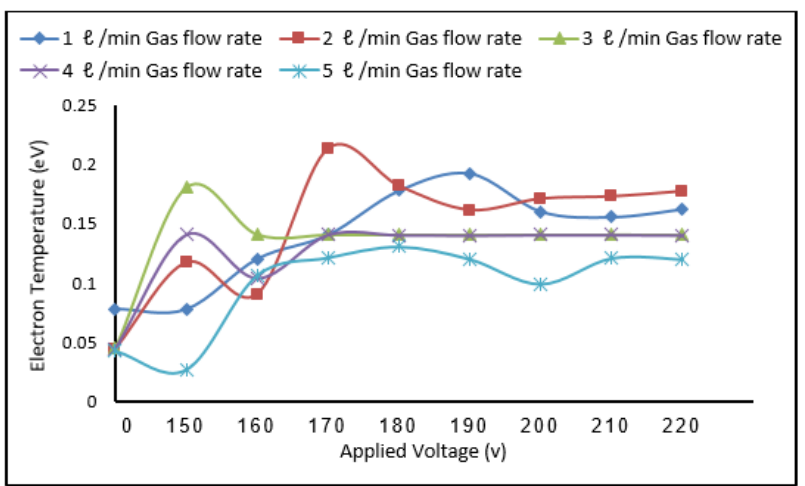

Figure 3. Effect of gas flow rates on the electron temperature and applied voltage.

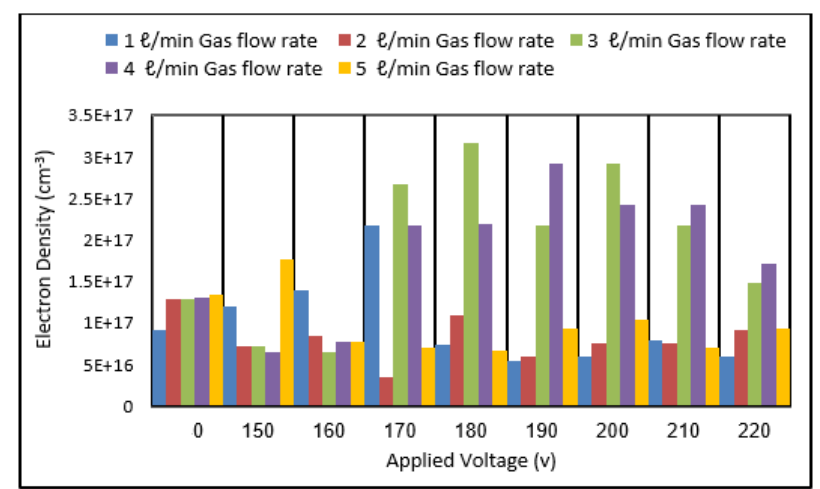

Figure 4. Effect of gas flow rate on the electron density and applied voltage.

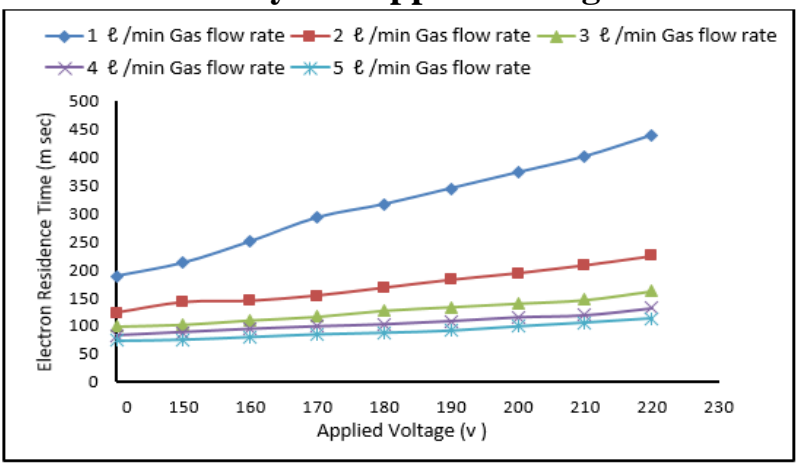

Figure 5. Effect of gas flow rate on the electron residence time and applied voltage.

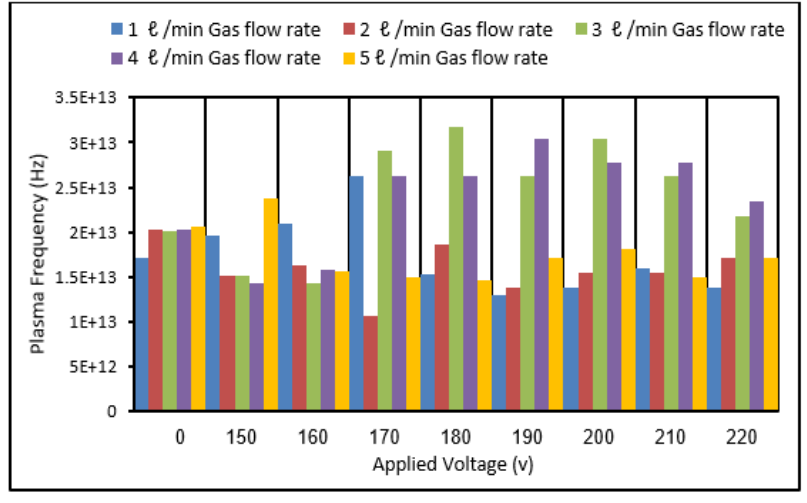

Figure 6. Effect of gas flow rate on the plasma frequency and applied voltage.

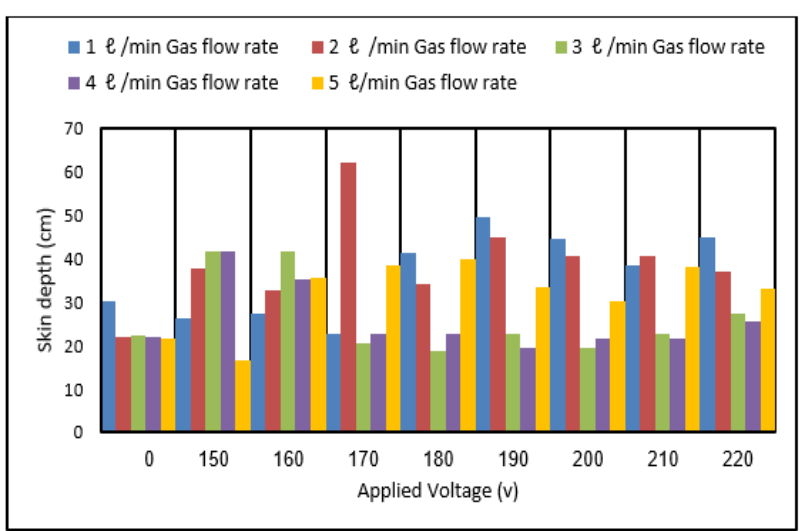

Figure 7. Effect of gas flow rate on the skin depth and applied voltage

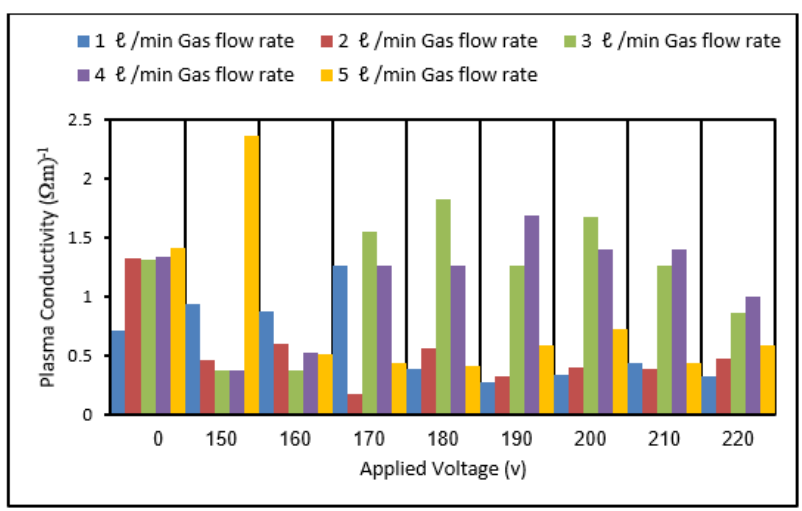

Figure 8. Effect of gas flow rate on the plasma conductivity and applied voltage.

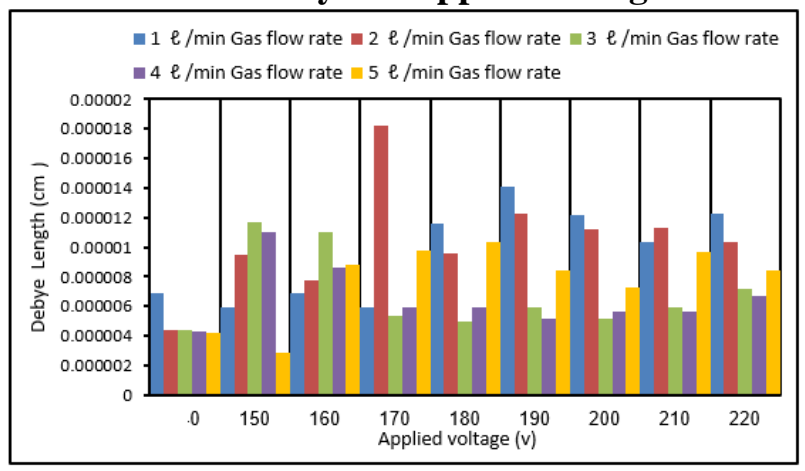

Figure 9. Effect of gas flow rate on the Debye length and applied voltage 


\section{Conflicts of Interest: None.}

\section{References:}

1. Szabó, D. Schlabach, S. Microwave Plasma Synthesis of Materials-From Physics and Chemistry to Nanoparticles. A Materials Scientist's Viewpoint Inorganics. 2014; 2( 3): 468-507.

2. Mazhir, SN. Ali,A. H. Abdalameer, N. K. Hadi,F. W. Studying the effect of Cold Plasma on the Blood Using Digital Image Processing and Images Texture analysis. International conference on Signal Processing. Communication, Power and Embedded System (SCOPES) IEEE Xplore Digital Library.2016: 904-914.

3. Ali, A. H. Al-Ahmed, H. Mazhir, S.N. Aiyah, S.N. Using texture analysis image processing technique to study the effect of microwave plasma on the living tissue. Baghdad Science Journal.2018;15(1):87-97.

4. Moisan,M. Zakrzewski, Z. Plasma sources based on the propagation of electromagnetic surface waves. J. Phys. D, Appl. Phys.1991; 24:1025-1048.

5. S. N. Mazhir, F. W. Hadi, A. N. Mazher, L. H. Alobaidy. 2017. Texture Analysis of smear of Leukemia Blood Cells after Exposing to Cold Plasma. Baghdad Sci. J. 2017; 14(2): 403-410.

6. Takamura,S. Takamura, S. Amano, T. Kurata, H. Kasada, J. Yamamoto, M. A. Razzak. Formation and decay processes of $\mathrm{Ar} / \mathrm{He}$ microwave plasma jet at atmospheric gas pressure. J. Appl. Phys.2011;110(4):043301-1-043301-8.

7. Leins,M. Kopecki, J. Gaiser,S. A. Schulz, M. Walker, U. Schumacher, U. Stroth, T. Hirth. Microwave plasmas at atmospheric pressure. Contrib. Plasma Phys.2014;54(1):14-26.

8. Hassouba, M Dawood,N. A Comparative Spectroscopic Study on Emission Characteristics of
DC and RF Discharges Plasma using Different Gases, Life Sci. J. 2014;11( 9): 656-666.

9. Aadim. KA Detection of laser-produced tin plasma emission lines in atmospheric environment by optical emission spectroscopy technique. Photonic Sensors. 2017; 7;6-7.

10. National Institute of Standards and Technology (NIST) atomic spectra database, (version5). Available at http://www.nist.gov/pml/data/asd.cfm, last updated: November 2, 2015.

11. Poueyo-Verwaerde,A. Fabbro,R. G. Deshors, A. M. De Frutos, J. M. Orza. Experimental Study Of LaserInduced Plasma In Welding Conditions With Continuous $\mathrm{CO}_{2}$ Laser J. Appl. Phys.1993; 74( 9): 5773-5780.

12. Szymanski, Z. Kurzyna. J. Spectroscopic Measurements Of Laser Induced Plasma During $\mathrm{CO}_{2}$ Laser. J. Appl. Phys. 1994;76( 12):7750-7756.

13. Wasfi A. S., H. R. Humud, M. E. Ismael, 2015. Spectroscopic Measurements of The Electron Temperature in Low Pressure Microwave $2.45 \mathrm{GHz}$ Argon Plasma. Iraqi J. Phys. 2015; 13(27): 14-24.

14. Tu,X. Cheron, BG. Yan, JH. Cen, KF. Electrical And Spectroscopic Diagnostic Of An Atmospheric Double Arc Argon Plasma Jet. Plasma Sources Sci. Technol. 2007;16( 4): 803-812.

15. Wolf, D. Resnick. W. Residence Time Distribution in Real Systems. Industrial and Engineering Chemistry Fundamentals. 1963;2(4):287-293.

16. Dinklage. A. Plasma Physics, Lect. Notes Phys. Springer, Berlin Heidelberg. 2005.

17. Bellan, PM Fundamentals of plasma physics. Academic press, New York,2004.

18. Mazhir SN. Spectroscopic Study of (TiO2)1-x(CuO)x Plasma Generated by Nd: YAG Laser. ARPN J. Eng. Appl Sciences. 2018;13(3):864-869.

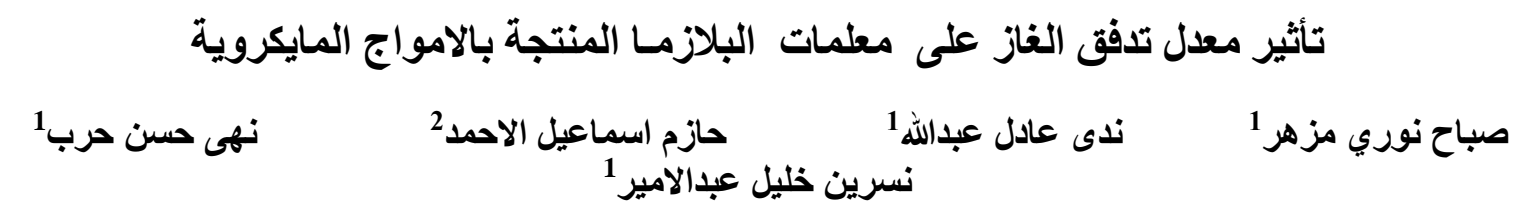

$$
\begin{aligned}
& 1 \text { قسم الفيزياء، كلية العلوم للبنات، جامعة بغداد، العراق. }
\end{aligned}
$$

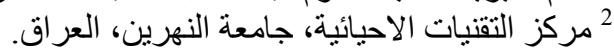

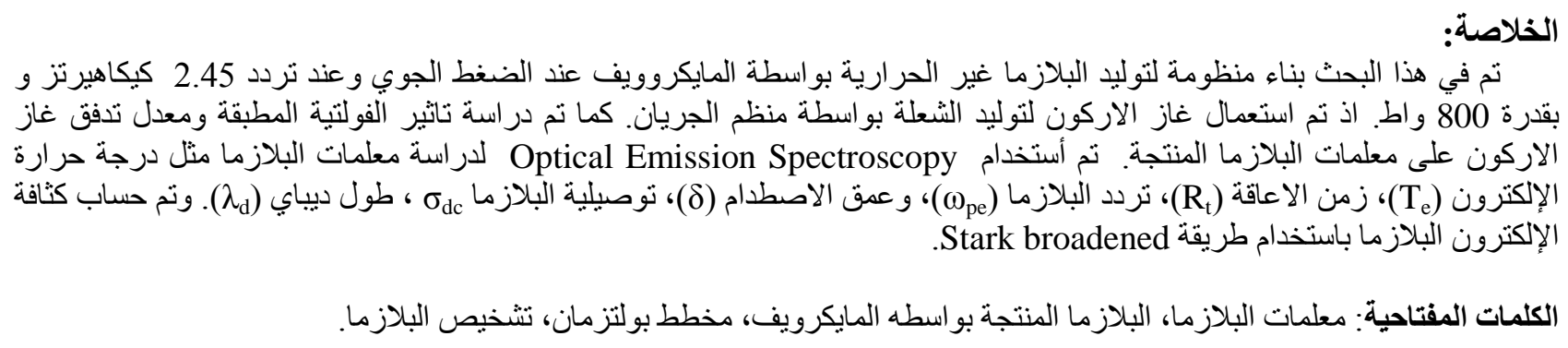

